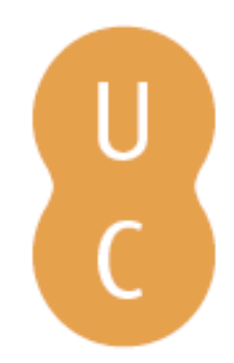

\title{
pommalina
}

\section{"A Europa: entusiasmo e questionação"}
Autor(es): $\quad$ Monteiro, Maria da Assunção Morais
Publicado por: Imprensa da Universidade de Coimbra
URL
persistente:
URI:http://hdl.handle.net/10316.2/38969
DOI:
DOI:http://dx.doi.org/10.14195/978-989-26-0395-7_23

Accessed : $\quad$ 26-Apr-2023 11:51:07

A navegação consulta e descarregamento dos títulos inseridos nas Bibliotecas Digitais UC Digitalis, UC Pombalina e UC Impactum, pressupõem a aceitação plena e sem reservas dos Termos e Condições de Uso destas Bibliotecas Digitais, disponíveis em https://digitalis.uc.pt/pt-pt/termos.

Conforme exposto nos referidos Termos e Condições de Uso, o descarregamento de títulos de acesso restrito requer uma licença válida de autorização devendo o utilizador aceder ao(s) documento(s) a partir de um endereço de IP da instituição detentora da supramencionada licença.

Ao utilizador é apenas permitido o descarregamento para uso pessoal, pelo que o emprego do(s) título(s) descarregado(s) para outro fim, designadamente comercial, carece de autorização do respetivo autor ou editor da obra.

Na medida em que todas as obras da UC Digitalis se encontram protegidas pelo Código do Direito de Autor e Direitos Conexos e demais legislação aplicável, toda a cópia, parcial ou total, deste documento, nos casos em que é legalmente admitida, deverá conter ou fazer-se acompanhar por este aviso. 
Nair de Nazaré Castro Soares

Santiago López Moreda

Coordenação

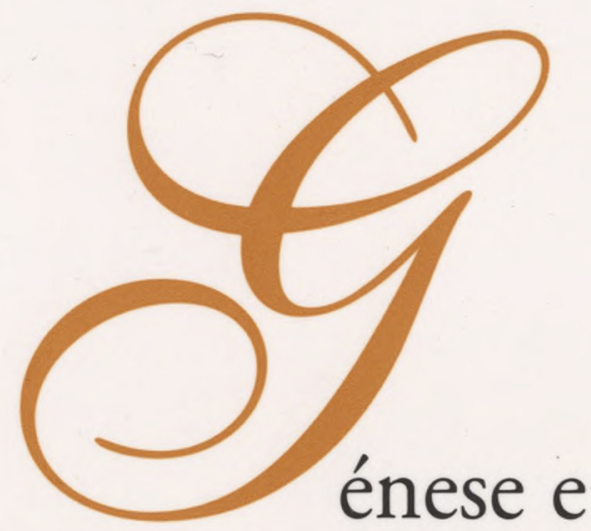

Consolidação da Ideia de Europa

Vol. IV

Idade Média e Renascimento

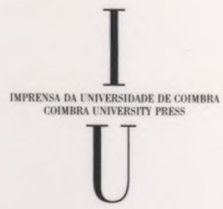

- COIMBra 2009 


\title{
"A EUROPA: ENTUSIASMO E QUESTIONAÇÃO"
}

\author{
Maria da ASSUnÇÃo Morais MONTEIRO \\ (Universidade de Trás-os-Montes e Alto Douro)
}

- Os Portugueses, europeus por nascimento, desde cedo sentiram necessidade de sair da Velha Europa para se expandirem por via marítima, o que levou aos Descobrimentos e à construção de um império que se estendeu pelos cinco continentes.

As façanhas desse tempo, realizadas em terra e no mar, foram imortalizadas por Luís de Camões na sua epopeia Os Lusiadas, autor que, segundo Miguel Torga, se tornou um "arquétipo" do português, um "paradigma do intelectual apegado ao ninho e solto, desassossegado, errante, aventureiro daquém e dalém mar, ávido de ver e saber, figuração perfeita da universalidade mental enraizada" (Torga 1990: 174-175).

Considerando que estamos no ano das comemorações do centenário do nascimento de Miguel Torga, ao longo deste trabalho vamos dar uma maior ênfase a este autor e à sua obra, pelo muito que falou da Europa, revelando a posição estratégica de Portugal como entrada neste continente, a sua admiração e entusiasmo face a ela, em contraste com Portugal, e ao mesmo tempo por ser uma das figuras da Literatura Portuguesa que mais questionou essa mesma Europa. Além disso, é uma forma de o homenagear através da evocação da sua obra.

Assim, apoiar-nos-emos em textos sobretudo do Diário, para salientar a necessidade que o povo português teve de sair do espaço europeu, para mostrar como foi senhor dos mares e quase senhor do mundo, acabando por, num percurso circular, ter de viver sedentarizado neste velho Continente.

Mostraremos também o entusiasmo torguiano pela Europa, o reconhecimento da sua civilização, superior em muitos aspectos, mas também as críticas que lhe faz e a forma como põe em causa a Europa dos tempos modernos.

Finalmente, registamos uma mensagem de esperança sobre o papel dos Portugueses na Europa da actualidade e no mundo. 
- Nascido na Europa Ocidental, o povo português desde sempre sentiu necessidade de se expandir, de ultrapassar os limites por onde começou. Inicialmente foram as guerras contra os Mouros, que lhe permitiram ir conquistando o território até ao Algarve, depois as viagens "por mares nunca de antes navegados", como escreveu Camões no Canto I, estância 1, no início da Proposição de Os Lusíadas (Camões 1989: 1).

Com a aventura ultramarina dos Descobrimentos, nos séculos XV e XVI, os Portugueses tornaram-se uma das grandes potências mundiais, um povo que abriu novos mundos ao Mundo e que Luís de Camões soube imortalizar no seu poema épico Os Lusíadas. Desde então Camões tornou-se um símbolo de Portugal e do Império Português.

A acção e repercussão das façanhas do povo luso desse tempo, não só a nível da Europa mas de todo o mundo, foi muito bem sintetizada por Miguel Torga no Diário XV, onde o define como um "povo temerário que abriu de par em par as evasivas portas ogivais da Idade Média, fez entrar por elas todo o sol promissor do Renascimento e planetarizou pela primeira vez o espírito" (Torga 1990: 28).

Quando se desloca a Macau no momento em que, não "em termos formais, mas em termos factuais", estamos "a despedir-nos de um recanto da pátria" (Torga 1990: 37-38) que se encontrava sob administração portuguesa há mais de quatrocentos anos, Miguel Torga, em 9 de Junho de 1987, ao falar de Camões, mostra bem a importância que este vulto da História, da Literatura e da Cultura assumiu ao longo dos séculos e revela também a importância d' $O s$ Lusíadas como símbolo da Portugalidade e da resistência à ocupação. Nos tempos da modernidade, a sua figura está presente como incentivo à construção de um futuro de comunhão europeia:

"Raramente um intelectual terá sido tão ferozmente livre de espírito e fiel à sua missão.

Em todas as horas da nossa vida cívica, é Camões que nos guia. No Ultimatum, cobrimos a sua estátua de crepes; no tempo dos Filipes, eram Os Lusíadas o livro da resistência. Agora, que atravessamos um período crucial da História, é ainda com ele no pensamento que poderemos encontrar ânimo para enfrentar o futuro. Um futuro que não será de ocupação, mas de comunhão." (Torga 1990: 36).

E, ainda a propósito d'Os Lusiadas e do seu autor, numa entrada do Diário $\mathrm{X}$, situada em Coimbra mais de duas décadas antes, em 14 de Novembro de 1966, Torga, depois de exprimir a sua concordância com Junqueiro, escreve:

"Junqueiro sabia: a língua é uma pátria. A pátria dum escritor, pelo menos. (...) Que são os Lusíadas senão um território idiomático, heroicamente conquistado às trevas da mudez, um espaço vital de expressão que o próprio verbo agenceia, baliza e preserva? 
Depois que os escreveu, nunca mais Camões pôde ser desterrado. Fosse para onde fosse, levaria na bagagem de proscrito a voz portuguesa - voz que encarnou Portugal durante os sessenta anos filipinos e continua a encarná-lo séculos passados." (Torga 1968: 113-114)

Os Lusiadas são, para Miguel Torga, "a mais actual e objectiva epopeia de quantas se conhecem. E, comparativamente com outras, salienta a sua superioridade, fundamentando claramente as suas afirmações:

"A história mental da humanidade regista outras igualmente famosas. A de Gilgamesh, a Iliada, a Odisseia, a Eneida, e a própria Divina Comédia, que é uma epopeia de almas. Mas nenhuma como Os Lusíadas cantou a natureza com tanta naturalidade e flagrância, exprimiu o homem tão de acordo com o entendimento que ele hoje tem de si mesmo, e celebrou com igual justiça e perenidade um esforço civilizacional colectivo." (Torga 1990: 26)

Torga, um inconformado e insatisfeito, um "orfeu rebelde", um "homem, um artista e um revolucionário", que procurou contribuir "de algum modo para a subversão da ordem vigente e a edificação duma sociedade melhor" (Torga: 1990: 173), admira Camões e Os Lusiadas pela vitória sobre as trevas e a ignorância, tendo por base o conhecimento a partir da experiência dura da vida, perspectiva com a qual se identifica. Não são, pois, de estranhar as palavras seguintes:

"Tudo se encontra nesse prodigioso relato de insatisfação moderna a vencer as trevas da ignorância, a arredondar a concepção do mundo e a antever-lhe a harmonia futura. $\mathrm{O}$ homem é, finalmente, não mais um adorador limitado, mas um interrogador ilimitado. Duvida, congemina, verifica. (...) A ciência do passado, aceite sem discussão, à sombra da autoridade, é posta agora em causa, em nome da observação directa dos fenómenos." (Torga 1990: 26-27).

Camões revela uma mentalidade nova para a qual Torga chama a atenção. Realça o valor, a "modernidade inovadora surpreendente" da obra camoniana de exaltação do povo português, mas também a insatisfação e a questionação de mentalidades, sendo as viagens marítimas do tempo dos Descobrimentos equiparadas às viagens espaciais da actualidade, referindo ainda que "o saber de hoje é também de experiências feito, e os nautas que dobraram o Cabo das Tormentas são os astronautas que vão agora à lua" (Torga 1990: 30).

A aventura expedicionária dos Portugueses teve, como se sabe, repercussões indeléveis por toda a parte, havendo marcas da sua presença por todo o mundo e para todo o sempre, quer através da formação de novas pátrias, quer pela expansão da sua língua e da sua cultura, que chegaram a espalhar-se por todos os continentes. 
Camões, em Os Lusíadas, através das profecias, quer de Júpiter quer de Tétis, refere os continentes e os locais onde os Portugueses iriam exercer a sua influência. Assim, no Canto II, Júpiter, para tranquilizar Vénus, a chorosa filha que subiu ao Olimpo a queixar-se da falta de protecção dada aos Portugueses, diz-lhe, na estância 44, que hão-de ser esquecidos os Gregos e os Romanos devido aos feitos que os Portugueses hão-de praticar no Oriente, acrescentando, na estância 45, que "novos mundos ao mundo irão mostrando". Nas estâncias seguintes, encontramos a exemplificação através de casos concretos, como por exemplo, Ormuz, Diu, Goa, Cananor, Calecut, a Península de Malaca, navegando até ao longínquo mar da China.

Em relação à Europa, Camões, ao fazer a narração da viagem de descoberta do caminho marítimo para a Índia, relata como os navegadores portugueses foram bem recebidos em Melinde e como o rei desta localidade sentiu curiosidade de saber mais sobre aqueles visitantes (Canto II, est. 108):

"Agora lhe pergunta pelas gentes

De toda a Hespéria última, onde mora;

Agora, pelos povos seus vizinhos,

Agora pelos húmidos caminhos." (Camões 1989: 56)

E, na estância seguinte, a n ${ }^{\circ} 109$ do mesmo Canto II, é introduzido o discurso directo, pondo na boca do Rei de Melinde as seguintes palavras:

“ - «Mas antes, valeroso Capitão,

Nos conta (lhe dizia) diligente,

Da terra tua o clima e região

Do mundo onde morais, distintamente;" (Camões 1989: 56).

É no Canto III que, dando resposta às perguntas e pedidos do rei de Melinde, Vasco da Gama inicia o seu relato. A propósito da localização de Portugal, responde-lhe desta forma na estância $\mathrm{n}^{\circ} 20$ :

"Eis aqui, quási cume da cabeça

De Europa toda, o Reino Lusitano,

onde a terra se acaba e o mar começa" (Camões 1989: 64).

No Canto X, quando Tétis leva Vasco da Gama ao cimo de um monte, onde lhe mostra um globo, miniatura do mundo, apresenta-lhe os locais onde os Portugueses hão-de particar feitos gloriosos e, na est. 92, refere a Europa, elogiando-a pela sua superioridade, ao mesmo tempo se pode ver o contraste com África. Diz Tétis:

"Vês Europa Cristã, mais alta e clara Que as outras em polícia e fortaleza.

Vês África, dos bens do mundo avara, Inculta e toda cheia de bruteza;" (Camões 1989: 270). 
Se Canões, em Os Lusiadas, escreveu que Portugal ficava quase no cume da cabeça do continente europeu, Torga foca igualmente esta localização "marginal à Europa". A ambiguidade desta expressão leva a duas interpretações: uma que nos permite saber que fica no extremo; a outra sugere que está colocado à margem. Assim, o adjectivo "marginal" pode ser encarado tanto em termos geográficos, como de atraso face às " proezas técnicas e antropotécnicas" europeias. Na mesma citação que a seguir vamos transcrever nota-se que, se por um lado Portugal pode parecer atrasado e retrógrado em relação à Europa, por outro lado destaca-se dela pela sua superioridade em aspectos humanos que o Autor valoriza, um dos quais, a tolerância, que levou a que fosse o primeiro país a abolir a pena de morte e a conceder a independência a uma das suas maiores colónias. Escreve Miguel Torga em 25 de Setembro de 1988:

"Marginal à Europa, nem sempre a acompanhou nas suas proezas técnicas e antropotécnicas. E, nesse capitulo, à primeira vista, pode parecer retrógrado. Mas essa falsa inércia, esse ilusório sono letárgico, é apenas a paz de boa consciência de quem conhece o preço de certas cedências ao progresso. (...) No decorrer dos séculos, este povo pacífico, que sempre se soube defender e nunca soube agredir, aparentemente parado no tempo, foi a própria encarnação do espírito renovador, na tolerância, na curiosidade, na inventiva. O primeiro a abolir a pena de morte, a dar a independência a uma das suas maiores colónias, a dobrar os muitos cabos das Tormentas." (Torga 1990: 137-138)

A situação geográfica de Portugal funciona como posição estratégica de entrada na Europa por via maritima. Torga, a propósito do Brasil, salienta a importância que o nosso País assume para os brasileiros, pela origem comum, pelas raízes linguísticas e pelo acesso fácil de entrada na Europa. Escreve Torga a este respeito:

Coimbra, 16 de Janeiro de 1953 - Disse hoje mais ou menos isto a um escritor brasileiro: (...)

Não há dúvida que temos sangue comum, e que o sangue aproxima. É certo, também, que sempre o idioma português se há-de encontrar na raiz do brasileiro, $\mathrm{E}$ como o destino dispôs que a América do Sul seja uma réplica da Ibéria em desmedido, é de esperar que nela se prolongue o antagonismo temperamental que aqui na Península se verifica entre vizinhos, e que ele alimente em nós uma instintiva sintonização de irmandade. Arquivo do vosso começo, Portugal será pelos séculos dos séculos o cais natural do vosso desembarque na Europa. (Torga 1978: 162-164)

$\mathrm{O}$ que foi dito relativamente ao Brasil, poderia ser escrito em relação aos Países Africanos de Língua Oficial Portuguesa. 
Para Miguel Torga, Portugal é como uma "pequena pátria", "fundadora de novas pátrias" que "com os descobrimentos marítimos realizou a maior epopeia dos tempos modernos, arredondando definitivamente o globo nas mentes coevas" e que " ainda hoje ajuda a povoar e a unir o orbe, num fluxo migratório constante" (Torga 1990: 138). E isto porque, como refere no Diário XV, "É nossa sina não caber no berço. Desde os primórdios que somos emigrantes. O português pré-histórico já era aventureiro, navegador, missionário, semeador de cultura. Assim o entendem alguns estudiosos nacionais e estrangeiros, e eu concordo." (Torga 1990: 31).

Miguel Torga, numa "Meditação para servir de preâmbulo a um roteiro francês" sobre Portugal, escreveu:

"Há nações que nascem feitas e nações que se fazem. Portugal é das que se fizeram, contra todos e contra tudo, e nunca teve sossego nas fronteiras, que chegaram a situar-se nos cinco continentes." (Torga 1990: 136)

Na actualidade os Portugueses continuam a ser um povo de emigração, embora em muito menor escala do que há décadas atrás, cujos destinos alvo de interesse, consoante os tempos, foram preferencialmente o Brasil e outros países da América do Sul (com destaque para a Venezuela), o Canadá e Estados Unidos da América. A África, particularmente os territórios sob administração portuguesa, foi outro dos destinos e, sobretudo na última metade do séc. XX, alguns países da Europa, principalmente França, Alemanha, Luxembrugo e Suiça. Hoje Portugal já não é apenas um país de emigrantes, que partiram em busca de melhores condições de vida. Actualmente dá-se também o inverso e há muitos imigrantes estrangeiros, que almejam uma vida melhor e que sonham encontrar em Portugal a sorte que não soube sorrir-lhes nos seus países de origem.

O português é apresentado por Torga numa dupla faceta. No Diário XV considera-o dividido, coexistindo nele a "vocação planetária" que o torna "um cidadão do mundo" e a vontade de regressar à terra onde nasceu:

"E é essa vocação planetária, essa inquietação dispersiva que faz do português um peregrino das sete partidas, um cidadão do mundo. Despido de pruridos raciais, uma vez em terra alheia, miscigena-se, adapta-se, integra-se, mas sem perder nunca os traços nativos. E quando a saudade - um sentimento sem tradução afectiva e vocabular - o crucifica, regressa e retoma, na aldeia de onde saiu, o seu lugar de membro da junta de freguesia ou de mordomo da festa." (Torga 1990: 138).

Para Torga o arquétipo do português é Camões. Se não fosse a sua vida "pelo mundo em pedaços repartida», "a mais desgraçada que jamais se viu», não teria sido, segundo aquele autor, "o símbolo verdadeiro do nosso destino 
de filhos das tristes ervas, de nómadas do planeta, de humildes obreiros de obras valerosas, de sentimentais apaixonados não correspondidos, de crentes descrentes, de cordatos temperamentais, de sonhadores inveterados" (Torga 1990: 34-35). A juntar a tudo isto, Camões tinha "um génio portentoso", que o torna modelar. Por isso conclui:

\footnotetext{
"Daí que Camões possa ser, simultaneamente, o português comum e o seu arquétipo, e todos nos possamos louvar com propriedade, por antonomásia, na pátria de Camões, na língua de Camões, e, acrescento eu, na sina de Camões, porque todos constamos nela." (Torga 1990: 35)
}

A tendência do Português para a divisão, a existência de um eu duplo, preso ao ninho e que sente necessidade de se afastar dele e viajar pelo mundo, é salientada por Torga que a vê bem protagonizada em Camões, o poeta que tanto ama:

"Amar Camões, amei-o eu sempre, e é ele o meu paradigma do intelectual apegado ao ninho e solto, desassossegado, errante, aventureiro daquém e dalém mar, ávido de ver e saber, figuração perfeita da universalidade mental enraizada" (Torga 1990: 174-175).

A propensão errante, aventureira do Português levou-o à construção do Império do qual gradualmente acabaram por surgir estados autónomos (começando pelo Brasil cuja independência foi reconhecida em 1822). No entanto, depois da partida, ficou "a presença portuguesa em cada vínculo familiar, apelido, hábito, vocábulo, tempero, reza, monumento, ruína" (Torga 1990: 32).

$\mathrm{Na}$ qualidade de antigo emigrante no Brasil, para onde partiu na adolescência, Torga sentiu profundamente a dualidade de sentimentos de quem se sente dividido entre a realidade que deixou e a que encontrou. Em «O Drama do Emigrante Português», texto publicado em Traço de União, exprime de forma muito clara essa dualidade de sentimentos: "Gemer por Portugal no Brasil, e pelo Brasil em Portugal. Ougar num por alheiras, e no outro por feijão preto. Trazer o corpo e o espírito neste vaivém de grávida com desejos" (Torga 1969: 117). É essa mesma duplicidade de sentimentos que, como refere no mesmo texto, faz do emigrante "um ser bifronte, a olhar perpètuamente em duas direcções opostas, perplexo, ansioso por partir e regressar no mesmo instante, a chupar mangas e a desejar cerejas no paladar" (Torga 1969: 112).

Em relação à Europa, existe também uma dualidade de sentimentos em Torga. O seu Diário revela posições díspares, de entusiasmo e de questionação. Se como viajante, como homem de letras, como cidadão do mundo, o autor do Diário sente alguma sedução e entusiasmo perante a civilização europeia presente em vários países por onde viaja, no seu íntimo há também uma voz que 
se preocupa com a sua terra, os seus hábitos, a sua identidade cultural, que o leva a refutar qualquer tentativa de supremacia e a revelar, através da escrita, a sua discordância e/ou revolta.

A admiração torguiana pela Europa, que culturalmente considera superior ao seu Portugal, que tantas vezes criticou, está patente na citação que a seguir se transcreve, extraida do Diário XI, e que é reveladora de uma necessidade de novos ares culturais. Essa lufada de ar europeu é-lhe dada pela contemplação de quadros de três artistas plásticos: Picasso, Chagall e Vieira da Silva:

Caramulo, 23 de Março de 1969 - Necessitado de atravessar a fronteira de qualquer modo, vim visitar Picasso, Chagall e a Vieira da Silva, que, embora sumariamente, são três janelas abertas, por onde o vento da Europa areja esta atmosfera tísica. (Torga 1973:40)

Compreendemos a inclusão de Maria Helena Vieira da Silva neste conjunto, uma vez que, embora tenha nascido em Lisboa, em 1908, desde jovem partiu para Paris, tendo-lhe sido concedida a naturalidade francesa, em 1956, país onde desempenhou um papel relevante no panorama da arte internacional.

A ideia de uma Europa "civilizada", em contraste com Portugal, é transmitida por Torga também quando, com alguma amargura, tem um desabafo como este que a seguir se transcreve, mostrando quanto sente a falta de uma presença portuguesa, a nível cultural, pela Europa fora, nos países por onde viaja:

"Capri, 16 de Setembro [1950] - Quando encontrarei eu numa livraria, num museu, ou mesmo num lugar bonito destas Europas civilizadas, um nome português à minha espera? Que triste sorte! Chega um homem ao Prado, nada! Percorre o Louvre, pior! Entra nas galerias do Vaticano, e ao todo, de nosso, encontra lá o estafado mapa do Tratado de Tordesillas!" (Torga 1974: 134)

Mas, apesar de ser muito crítico em relação ao que de errado vê no seu país, Torga, noutros momentos não deixa de manifestar o seu entusiasmo por Portugal. Após uma viagem por vários países da Europa Ocidental (Espanha, França, Itália, Suiça), iniciada em Espanha em finais de Agosto, prolongada por todo o mês de Setembro e princípios de Outubro, quando vai à Serra da Lousã, em 5 de Novembro de 1950, tem este desabafo sobre o seu Portugal, tão diferente dos países por onde viajou:

"Portugal! É por sabê-lo tão pobre e tão atormentado que o amo tanto e o respeito tanto. Numa Europa de pátrias femininas, enternece-me vê-lo masculino, seco, garanhão, de fundilhos nas calças, a fazer namoro a tanta mulher anafada e bem vestida." (Torga 1974: 165) 
Torga criticava o Portugal do seu tempo e, em muitas situações, considerava-o inferior à Europa, que lhe fornecia referências culturais, históricas e politicas. Depois de viajar por França, Bélgica, Holanda, Andorra e Espanha, evidencia o reconhecimento das diferenças entre o Portugal do tempo e os paises europeus. A entrada seguinte, do Diário VIII, situada em Coimbra, 16 de Junho de 1958, é reveladora de uma crítica irónica e sibilina ao Portugal desse tempo, bem diferente de outros países europeus:

"Coimbra, 16 de Junho de 1958 - Felizes os que nunca daqui saíram, ou foram e vieram na mesma cegueira. Um português que passeia pela Europa, e no regresso continua a acreditar que somos os melhores do mundo, está na graça de Deus." (Torga 1976: 129).

Ao mesmo tempo que reconhece as diferenças entre Portugal e a Europa, Torga também não deixa de criticar o que de negativo encontra no velho Continente. Conhecido pelo seu humanismo, autocaracterizou-se no Diário XVI, em 1993, como um "defensor incansável do amor, da verdade e da liberdade, a triade bendita que justifica a passagem de qualquer homem pelo mundo" (Torga 1993: 200). Estas suas preocupações estão patentes em muitos momentos do seu Diário, um dos quais quando viaja pela Alemanha e tem um desabafo de indignação e vergonha perante o Muro de Berlim, construído em 1961. São cerca de $150 \mathrm{~km}$ de extensão que, para além de dividir a cidade, separou as pessoas, privando-as da liberdade de se deslocarem de um lado para o outro:

"Berlim, 28 de Agosto de 1970 - Pego na caneta indignado e envergonhado ao mesmo tempo. Como foi possível, depois de tanta luta, de tanto sofrimento, de tantas mortes e de tanta esperança, que se erguesse no coração da Europa esta barreira de ódio?" (Torga 1973: 107).

E, ainda a propósito da mesma "barreira de ódio", encontramos dois registos importantes, ambos de 1989, havendo um lapso de tempo de pouco mais de dez meses entre os dois. Neles se evidenciam os propósitos em relação ao muro e, em seguida, os factos. O primeiro é de Janeiro e diz o seguinte:

“Coimbra, 20 de Janeiro de 1989 - O presidente da República Democrática Alemã declarou que o muro de Berlim vai durar mais cem anos. Diz o povo português, e, se calhar, o germânico também, que quem muito abarca pouco abraça. Parar o tempo, só Josué... e na Bíblia." (Torga 1990: 158). 
O outro registo é de Novembro desse mesmo ano e traduz a mudança, as consequências dela e o pensamento de Torga sobre o assunto, mostrando quão importante considera a sua destruição:

"Coimbra, 9 de Novembro de 1989 - Ruiu o muro de Berlim. O cimento marxista não resistiu ao empurrão de milhões de vontades represadas. $\mathrm{A}$ ironia das coisas! Erguido para impedir a fuga de alguns, acabou por ser aberto para evitar o êxodo de todos. A sua destruição ficará nos anais como o mais significativo acontecimento deste fim de século." (Torga 1990: 188).

E, logo a seguir, confirma a indignação e vergonha que sentiu e registou quando o viu ao natural, em 1970, mostrando também quão absurda era a sua existência:

"É que não era uma simples, feia e absurda parede a dividir um povo. Era o símbolo concreto da dicotomia trágica em que temos vivido. Dum lado, os purificados; do outro, os pestíferos. Só quem um dia o viu ao natural, eriçado de arame farpado e de metralhadoras, pode avaliar a vergonha e humilhação que ele representava para o espírito humano. Agora, pronto. Já se podem trocar as virtudes, os vícios e as ideias. E olhar livre e fraternalmente em todas as direç̧ões." (Torga 1990: 188)

Nem sempre existe um elogio à Europa e aos países europeus, como tivemos oportunidade de constatar. Em outros momentos do seu Diário, Torga critica o velho Continente pelas influências que está a sofrer e das quais discorda com veemência:

"Coimbra, 23 de Novembro de 1955 - Visita dum professor norte-americano, que durante horas, numa inocência mental e num primarismo lógico de arrepiar, me deu a medida do tenebroso futuro que nos espera. É preciso que a Europa ocidental tenha chegado às últimas, à extremidade da pobreza material e aos limites da decadência social, para se sujeitar a receber ordens de tal gente." (Torga 1976: 24).

E, num outro registo, critica a mesma Europa, por se deixar envolver em guerras com as quais Torga não concorda. As suas palavras são muito duras e contundentes. Recorrendo à linguagem metafórica e ao processo irónico, usa expressões como "filme pornográfico" e "fogo de artifício dos bombardeamentos" para falar do conflito:

"Coimbra, 21 de Janeiro de 1991 - Continua o filme pornográfico da guerra no Golfo. Em vez de mulheres nuas, o fogo de artificio dos bombardeamentos. Os papéis a que esta pobre Europa se presta ou é obrigada!" (Torga 1993: 58) 
Ainda que constate a superioridade europeia em termos de civilização em relação a outros continentes como a América, não deixa de, em 1942, reconhecer que a Europa está a deixar-se ultrapassar por aqueles que por ela foram colonizados:

"Teima a Europa, culta, velha, experiente, mas anacrónica, em que a vida dos povos é sobretudo história. Que, por isso, o facho da autêntica civilização é seu, e só na sua posse deve caminhar. Tudo verdades como punhos. Mas o certo é que o facho lhe está dia-a-dia a morrer nas mãos e a passar para as mãos selvagens dos seus colonos. Com a mesma luminosidade? Evidentemente que não, mas que importa? A vida não se move por acções lógicas. Move-se por imponderáveis, e sobretudo pela força dos factores." (Torga 1977: 42-43).

Apesar de considerar que a Europa "dia a dia masoquisticamente se desfigura, como que envergonhada da sua nobre identidade" (Torga 1993: 140), ainda acredita na "vitalidade deste nosso atribulado continente", afirmando que:

"Nenhum tratado de Maastricht, por mais que queiram, pode apagar da memória ocidental os vitrais de Chartres ou as páginas de Proust. Nuns e noutras brilha, encantado, o sol perene do milagre bíblico que outros Josués menos míticos, de que só depois de muito peregrinar $\mathrm{e}$ aprender tive a revelação, repetem humilde $\mathrm{e}$ obstinadamente, em todas as latitudes, num desafio heróico à miopia pragmática duma época sem alma e sem imaginação" (Torga 1993: 140-141).

Podemos afirmar que a posição de Torga face à Europa é de alguma forma semelhante à que escreveu acerca do seu iberismo:

"O meu iberismo é um sonho platónico de harmonia peninsular de nações. Todas irmãs e todas independentes. Mas é também uma paixão escabreada, que arrefece mal se desenha no horizonte qualquer sinal de hegemonia política, económica ou cultural. Que exige reciprocidade na sua boa fé e nos seus arroubos. Que quer apenas comungar fraternamente num mais largo espaço de espiritualidade." (Torga 1990: 133)

A rebeldia inerente ao espírito torguiano impede-o de aceitar a imposição de qualquer hegemonia política, económica e cultural. É por isso que a entrada de Portugal na Comunidade Europeia é vista por ele com alguma apreensão, pela possível perda de autonomia, liberdade e identidade. Na sequência de ouvir alguém que "tais ditirambos ergueu à nossa entrada no Mercado Comum, à felicidade que nos espera no seio materno da comunidade europeia", Torga escreve no Diário XVI:

"Pedi a Deus alto e bom som, que assim fosse, e possamos continuar a ter voz própria, identidade, e direito a um território livre e autónomo que não receba diariamente ordens alheias de cultura e cultivo, e seja obrigatoriamente transformado num eucaliptal." (Torga 1993: 84) 
E, no mesmo volume do Diário, em nota de Coimbra, 1 de Novembro de 1991, a propósito da entrada em vigor da União Europeia, deixa transparecer toda a sua amargura pelo que considera uma perda de autoridade e pela atitude de subserviência que, a seu ver, passou a existir. Vejamos as suas palavras amargas:

"Entrada em vigor da União Europeia, eufemismo encontrado para nomear o negregado Tratado de Maastricht. Lá estamos, atentos à batuta do novo Bismark impante que tudo vai poder e dominar do seu teutónico quartel monetário. Lá estamos, infelizmente, na condição de humildes súbditos, agradecidos, sem autonomia e sem voz, a beber champanhe comprometidamente, como parentes pobres numa boda de nababos, e a estender a mão ávida, a pedir mais dinheiro para comprar votos. E o ricaço, e os parceiros incautos que arregimentou, prodigamente, abrem os cordões à bolsa. Quem quer bons serviçais, paga-lhes." (Torga 1993: 187).

É sarcástica esta crítica de Torga. A nota imediatamente anterior, datada de 31 de Outubro de 1993, revela o seu desânimo e preocupação:

"Estamos irremediavelmente perdidos. (...) Um povo que já foi senhor da sua vontade e dos seus actos, mas que muitos anos de obscurantismo, de inquisição e ditadura degradaram e perverteram, e agora, de novo tiranizado, insofrido e impotente, geme. Oiço esse gemido insistente e generalizado, e fico transido." (Torga 1993: 186).

Torga, sobretudo na escrita diarística, deixou expressas preocupações com o que se passava à sua volta, em Portugal e no mundo. O seu Diário não é um banal diário quotidiano, escrito por alguém que se refugia nele para extravasar o que lhe vai na alma. É muito mais do que isso, na medida em que serve para testemunhar e perpetuar factos ocorridos durante várias décadas do séc. XX e tomadas de posição em relação a eles. Mais do que um diário intimista é um diário que contém muitos eventos importantes da História da Humanidade e que apresenta uma particularidade relativamente à grande maioria dos diários escritos anteriormente: é de publicação ântuma, o que compromete o Autor com as ideias veiculadas e o responsabiliza perante os seus contemporâneos e os vindouros.

Quem quiser fazer a História do Portugal do séc. XX, tem no Diário de Torga um manancial de informações que ajudam a fazer a História deste pequeno país da Europa, do qual os Portugueses partiram, tornando-se senhores dos mares e do mundo, para, num percurso circular, a ele regressarem e se "sedentarizarem".

- Depois do 25 de Abril de 1974, e com a independência dos territórios que estiveram sob a jurisdição portuguesa, após um tão extenso império de que foram senhores, é à Europa que os Portugueses têm de se restringir. 
Torga, chamando a atenção para o facto de o povo português nunca ter cabido neste canto da Europa, de nunca se ter sentido realizado nela e ter tido a necessidade de se expandir pelo mar, agora que a situação mudou, tem de passar de nómada e cidadão do mundo a povo sedentarizado na velha Europa. Vejamos esta citação do Diário XII:

“Coimbra, 27 de Julho de 1974 - Vamos finalmente dar independência aos povos colonizados. Uma independência que sem dúvida lhes irá custar cara, mas não há nenhuma que seja barata. Depois desse acto necessário e imperioso, Portugal ficará reduzido à tal nesga de terra debruada de mar. É a História que o exige, e oxalá que o destino também. (...) Nómadas do mundo, teremos de ser agora sedentários conviventes nesta Europa onde sempre coubemos mal e nunca nos soubemos realizar. Partir era a nossa carta de alforria. Hoje os caminhos não serão já os da demanda de espaços abertos a uma afirmação tolhida no berço, mas os de um achamento interior protelado séculos a fio." (Torga 1986: 76-77)

Torga distingue o ser europeu por nascimento do ser europeu de direito, isto é, como resultado da entrada de Portugal na Comunidade Europeia. Escreve em 28 de Março de 1985:

\begin{abstract}
"Parece que sempre vamos entrar no Mercado Comum. Que em breve passaremos a ser europeus de direito. De facto, já o éramos desde o nascimento, mas sempre a trocar obstinadamente as voltas à geografia, fazendo-nos, mal largávamos os cueiros, ciganos do mundo. Era o instinto a apontar-nos um caminho na vida de afirmação singular. Agora, as vicissitudes da história, e erros clamorosos cometidos, obrigamnos a assumir a condição caseira de sedentarizados neste velho continente. Um passo decisivo que vai pôr à prova em termos dramáticos a nossa capacidade adaptativa e criativa. Ou ganhamos tudo ou perdemos tudo." (Torga 1987: p. 156).
\end{abstract}

E, como refere logo a seguir, no mesmo texto, até aqui só fomos confrontados com povos exóticos de pouco ou nenhum significado em termos de competitividade moderna, mas agora o desafio é muito maior, na medida em que estamos perante a Europa, "enfrentamos os corifeus da civilização a que pertencemos e a que demos nos bons tempos uma contribuição específica que a planetarizou" (Torga 1987: 156-157). Daí a necessidade de nos adaptarmos aos seus métodos e práticas, a necessidade de mudar de comportamento, mantendo sempre a nossa identidade. E é por esse motivo que Torga exprime o seguinte desejo:

"Oxalá que, forçados a mudar de comportamento, o façamos conscientemente e apenas como enriquecimento do que fomos e somos, sem perda de nenhuma das virtudes que nos caracterizam e dão jus a um posterior destino só por nós talhado. 
E que um dia (...) nos possamos orgulhar de ter estado idênticos a nós próprios, à altura do desafio, e sejamos capazes de escrever, com o mesmo génio de outrora, uma nova Peregrinação, desta vez portas a dentro, igualmente inverosímil e verdadeira." (Torga 1987: 157).

É uma mensagem de esperança que Torga, em 28 de Março de 1985, escreve no Diário para deixar aos seus coetâneos. E isto porque como escreveu mais tarde, "não somos um povo morto, nem sequer esgotado". Somos um povo que tem:

"um grande papel a desempenhar no seio das nações, como a mais ecuménica de todas. $\mathrm{O}$ mundo não precisa hoje da nossa insuficiente técnica, nem da nossa precária indústria, nem das nossas escassas matérias-primas. Necessita da nossa cultura e da nossa vocação para o abraçar cordialmente, como se ele fosse o património cultural de todos os homens". (Torga 1990: 37).

É esse, entre muitos outros, o papel que os Portugueses terão de desempenhar, na Europa da actualidade e no Mundo, sem pôr de parte a sua técnica, a sua sabedoria e as suas invenções.

\section{REFERÊNCIAS BIBLIOGRÁFICAS}

CAmões, Luís de (1989): Os Lusiadas (prefácio de Álvaro Júlio da Costa Pimpão, apresentação de Aníbal Pinto de Castro), $2^{\mathrm{a}}$ edição. Lisboa: Instituto de Cultura Portuguesa: Ministério da Educação.

TORGA, Miguel (1968): Diário X. Coimbra: Edição do Autor. , Miguel (1969): Traço de União, $2^{\mathrm{a}}$ edição revista. Coimbra: Edição do Autor.

, Miguel (1973): Diário XI. Coimbra: Edição do Autor.

_, Miguel (1974): Diário V, $3^{\text {a }}$ edição revista. Coimbra: Edição do Autor.

_, Miguel (1976): Diário VIII, $3^{\text {a }}$ edição revista. Coimbra: Edição do Autor.

, Miguel (1977): Diário II, $4^{\text {a }}$ edição. Coimbra: Edição do Autor.

, Miguel (1978): Diário VI, $3^{\text {a }}$ edição. Coimbra: Edição do Autor.

, Miguel (1986): Diário XII, $3^{\text {a }}$ edição revista. Coimbra: Edição do Autor.

, Miguel (1987): Diário XIV. Coimbra: Edição do Autor.

, Miguel (1990): Diário XV. Coimbra: Edição do Autor.

, Miguel (1993): Diário XVI. Coimbra: Edição do Autor. 